\title{
COMPARISON OF HEMORRHOIDECTOMY VERSUS HEMORRHOIDECTOMY AND INTERNAL SPHINCTEROTOMY IN TERMS OF POSTOPERATIVE PAIN.
}

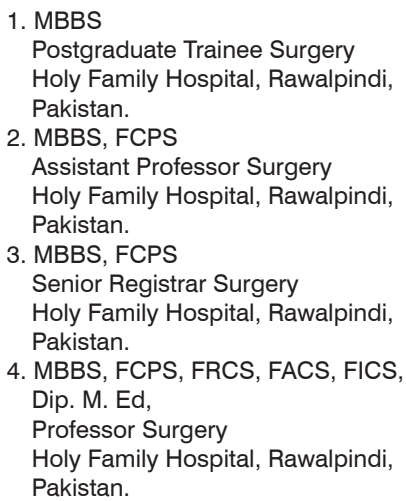

4. MBBS, FCPS, FRCS, FACS, FICS,

Dip. M. Ed,

Professor Surgery

Holy Family Hospital, Rawalpindi, Pakistan.

Correspondence Address: Dr. Muhammad Salman Shafique House no. 506-A, Street no. 11, Margalla Town, Islamabad.

f_salman07@hotmail.com

Article received on:

17/10/2018

Accepted for publication:

$31 / 07 / 2019$

\begin{abstract}
Afiya Zulfikar ${ }^{1}$, Usman Qureshi ${ }^{2}$, Muhammad Salman Shafique ${ }^{3}$, Jahangir Sarwar Khan ${ }^{4}$
\end{abstract}
\begin{abstract}
Objectives: To compare open hemorrhoidectomy with internal sphincterotomy versus open hemorrhoidectomy alone in terms of frequency of the postoperative pain. Study Design: Randomized Controlled Trial. Setting: Surgical Unit - I, Holy family Hospital, Rawalpindi. Period: January 2016 to December 2016. Material \& Methods: 250 patients were divided in two equal groups by lottery method. The surgical procedure was performed using standard protocols after obtaining written informed consent. Anal dilatation was done after open hemorrhoidectomy in patients of control group (Group A). In the study group (Group $\mathrm{B})$, the patients were subjected to lateral internal sphincterotomy after completion of classical open hemorrhoidectomy. Postoperative pain score was recorded by using visual analog scale. Difference between both groups for pain was analyzed using chi-square test. Results: There were 68 males and 57 females in Group-A and 61 males and 64 females in Group-B. The mean age of patients in Group-A was 33.10 \pm 8.77 years and in Group-B was 32.52 \pm 9.4 years. The mean pain score of patients in Goup-A and Group-B was 2.82 \pm 2.51 and $1.59 \pm 1.58$ respectively $(\mathrm{P}<0.05)$. In Group-A, $94(75.2 \%)$ cases had no pain while in Group-B, 116 (92.8\%) cases were pain free following the procedure. The difference between both groups was significant i.e. $\mathrm{P}<0.05$. Conclusion: Open hemorrhoidectomy with internal sphincterotomy is effective in reducing postoperative pain.
\end{abstract}

Key words: $\quad$ Hemorrhoids, Internal Sphincterotomy, Open Hemorrhoidectomy, Postoperative Pain.

Article Citation: Zulfikar A, Qureshi U, Shafique MS, Khan JS. Comparison of hemorrhoidectomy versus hemorrhoidectomy and internal sphincterotomy in terms of postoperative pain. Professional Med J 2020; 27(4):677-681. DOI: 10.29309/TPMJ/2020.27.04.221

\section{INTRODUCTION}

Hemorrhoids arise from congestion of anal cushions and characteristically lie in the 3, 7 and 11 O' clock positions (with the patient in lithotomy position). ${ }^{1}$ Symptoms may include bright red painless bleeding, mucus discharge, prolapse. $^{2}$ They are commonly classified by the traditional Goligher's grading of I to IV. ${ }^{1}$

Various treatment modalities have been described for the treatment of hemorrhoids like injection sclerotherapy, rubber band ligation, infrared photocoagulation, bipolar diathermy, closed hemorrhoidectomy, open hemorrhoidectomy, and stapled hemorrhoidopexy. ${ }^{3}$ Classically, the gold standard treatment for Grade II, Grade III and Grade IV hemorrhoids, which are unresponsive to other non-surgical approaches, is Milligan-
Morgan operation. ${ }^{4}$

The main complication of hemorrhoidectomy is the uncomfortable pain in the first postoperative week. $^{5}$ This pain is attributable to spasm of the internal sphincter that is exposed after open hemorrhoidectomy, especially in younger patients with higher anal tone. ${ }^{6}$

Various methods have been tried in order to reduce post hemorrhoidectomy pain. Internal sphincterotomy is a safe and rapid procedure with less postoperative pain and complication rate. ${ }^{6}$ Sphincterotomy abolishes the hypertonicity (spasm/pressure) of the internal anal sphincter and subsequently reduces postoperative pain. ${ }^{5}$

In a trial performed by Raza et al, postoperative 
pain was present in 44.4\% (24 out of 54) patients who underwent hemorrhoidectomy with internal sphincterotomy as compared to $98.1 \%$ (53 out of 54) patients who had open hemorrhoidectomy done alone $(P=0.000) .^{7}$

Most of the studies have done in comparison of post operative pain after hemorrhoidectomy. Both local and international data prefer hemorrhoidectomy with internal sphincterotomy. So the purpose of this study is to evaluate the effectiveness of internal sphincterotomy on post hemorrhoidectomy pain, so that we can use this procedure with confidence in our setup.

\section{MATERIAL AND METHODS}

A randomized controlled trial was conducted in Surgical Unit-I, Holy Family Hospital, Rawalpindi, from January, 2016 to December, 2016. Approval for this study was taken from Institutional Research Forum of Rawalpindi medical college (RMC) and hospital authorities.

Two hundred and fifty (250) patients of either gender, age ranging from 18 to 50 years and Grade II, Grade III and Grade IV hemorrhoids in whom conservative approaches failed were admitted through OPD on an elective basis and enrolled in the study. Patients with recurrent hemorrhoids, additional anorectal pathology (fistula in ano, anal fissures etc.), any neurological deficit and chronic pain syndrome were excluded.

Using lottery method, 125 patients were randomly allocated to each study group A and group B. A written informed consent was obtained from the patients before the surgical procedure. All patients underwent surgery in the lithotomy position under spinal anesthesia. The surgical procedure was performed using standard protocol. Open hemorrhoidectomy alone was done in group A (control group) patients. In group B (study group), lateral internal sphincterotomy was also performed along with standard open hemorrhoidectomy. All the patients received a standard postoperative analgesia regimen containing intravenous tramadol $100 \mathrm{mg}$. Postoperative pain score was recorded daily for two days by a resident doctor, using visual analog scale (VAS). A standardized data collection form was used to record all the findings.

Data was analyzed using SPSS software (Version 19). Frequencies and percentages were calculated for gender and grade of hemorrhoids. Quantitative variables such as age and pain scores were expressed as mean and standard deviation. Difference between pain frequencies between the two study groups were analyzed using chi-square test. $P$ value of $<0.05$ was considered statistically significant. Effect modifiers like age, gender, and grades of hemorrhoids were controlled by stratification. Post stratification chi square test was applied using 5\% significance level.

\section{RESULTS}

Out of 250 patients, 129 were males and 121 were females. There were 68 (54.4\%) males and $57(45.6 \%)$ females in control group (Group A) and 61 (48.8\%) male and 64 (51.2\%) female patients in the study group (Group B). Mean age of the patients in group $A$ was $33.10 \pm 8.77$ years whereas it was $32.52 \pm 9.4$ years in group $B$.

In Group A, 36 (28.8\%) cases had grade II hemorrhoids, 45 (36\%) had grade III, while grade IV hemorrhoids were found in 44 (35.2\%) patients. On the other hand, grade II, III \& IV hemorrhoids were seen in 39 (31.2\%), 40 (32\%) and 46 (36.8\%) patients in group $B$ respectively. This is shown in Table-I.

In group A, 24.8\% cases had pain in the postoperative period, while only $7.2 \%$ patients experienced postoperative pain in group B. (Table-II) The mean pain score of patients in Group A was $2.82 \pm 2.51$ on visual analog scale, while it was $1.59 \pm 1.58$ in the study group. This difference in mean pain scores between the two groups was statistically significant. $(P=0.000)$

Postoperative painscoreswerestratified according to age, gender and grade of heamorrhoids in both groups. The difference between both groups was statistically $(P<0.05)$ in all categories except for patients with grade IV haemorrhoids. (Table-III) 


\begin{tabular}{|l|c|c|c|}
\hline \multicolumn{2}{|c|}{ Treatment Group } & $\begin{array}{c}\text { Control Group (Group A) } \\
\text { (n= 125) }\end{array}$ & $\begin{array}{c}\text { Study Group (Group B) } \\
\text { (n= 125) }\end{array}$ \\
\hline Age (years) & Mean \pm SD & $33.10 \pm 8.77$ & $32.52 \pm 9.4$ \\
\hline Gender & Male & 68 & 61 \\
\hline & Female & 57 & 64 \\
\hline & II & 36 & 39 \\
\hline Grade of hemorrhoids & III & 45 & 40 \\
\hline & IV & 44 & 46 \\
\hline
\end{tabular}

Table-I. Descriptive statistics

\begin{tabular}{|l|c|c|c|c|}
\hline \multicolumn{2}{|c|}{ Treatment Group } & $\begin{array}{c}\text { Control Group } \\
\text { (Group A) } \\
(\mathbf{n = 1 2 5 )}\end{array}$ & $\begin{array}{c}\text { Study Group } \\
\text { (Group B) } \\
(\mathbf{n = 1 2 5 )}\end{array}$ & P-Value \\
\hline \multirow{2}{*}{ Post-operative Pain } & Present & $31(24.8 \%)$ & $09(7.2 \%)$ & \multirow{2}{*}{0.000} \\
\cline { 2 - 5 } & Absent & $94(75.2 \%)$ & $116(92.8 \%)$ & \\
\hline VAS Score & Mean \pm SD & $2.82 \pm 2.51$ & $1.59 \pm 1.58$ & \\
\hline
\end{tabular}

Table-II. Postoperative pain score in both groups

\begin{tabular}{|c|c|c|c|c|c|}
\hline \multirow{3}{*}{ Variable } & \multicolumn{4}{|c|}{ Treatment Groups } & \multirow{3}{*}{ P-Value } \\
\hline & \multicolumn{2}{|c|}{$\begin{array}{c}\text { Control Group } \\
\text { (Group A) } \\
(n=125)\end{array}$} & \multicolumn{2}{|c|}{$\begin{array}{c}\text { Study Group } \\
\text { (Group B) } \\
(n=125)\end{array}$} & \\
\hline & Present & Absent & Present & Absent & \\
\hline $\begin{array}{l}\text { Age } \\
\leq 30 \text { Years } \\
>30 \text { Years }\end{array}$ & $\begin{array}{l}08 \\
23\end{array}$ & $\begin{array}{l}38 \\
56\end{array}$ & $\begin{array}{l}07 \\
02\end{array}$ & $\begin{array}{l}48 \\
68\end{array}$ & $\begin{array}{l}0.512 \\
0.000\end{array}$ \\
\hline $\begin{array}{l}\text { Gender } \\
\text { Male } \\
\text { Female }\end{array}$ & $\begin{array}{l}16 \\
15\end{array}$ & $\begin{array}{l}52 \\
42\end{array}$ & $\begin{array}{l}05 \\
04\end{array}$ & $\begin{array}{l}56 \\
60\end{array}$ & $\begin{array}{l}0.019 \\
0.002\end{array}$ \\
\hline $\begin{array}{l}\text { Grade } \\
\text { of hemorrhoid } \\
\text { II } \\
\text { III } \\
\text { IV }\end{array}$ & $\begin{array}{l}09 \\
11 \\
11\end{array}$ & $\begin{array}{l}27 \\
34 \\
33\end{array}$ & $\begin{array}{l}00 \\
02 \\
07\end{array}$ & $\begin{array}{l}39 \\
38 \\
39\end{array}$ & $\begin{array}{l}0.001 \\
0.013 \\
0.246\end{array}$ \\
\hline
\end{tabular}

Table-III. Postoperative pain stratified for Age, Gender \& Grade of hemorrhoids in both groups

\section{DISCUSSION}

In this trial, the mean age of patients was $33.10 \pm 8.77$ years in open hemorrhoidectomy alone group (Group-A) and 32.52 \pm 9.4 years in open hemorrhoidectomy plus internal sphincterotomy group (Group-B). In open hemorrhoidectomy group, there were 68 males and 57 females. In open hemorrhoidectomy plus internal sphincterotomy group, there were 61 males and 64 females.

In Group-A, $36(28.8 \%)$ cases had grade II hemorrhoids, $45(36 \%)$ cases had grade III and
$44(35.2 \%)$ cases had grade IV hemorrhoids. In Group-B, 39 (31.2\%) cases had grade II hemorrhoids, $40(32 \%)$ cases had grade III and $46(36.8 \%)$ cases had grade IV hemorrhoids.

In our trial after surgery, the mean pain score was $2.82 \pm 2.51$ in Group-A while it was $1.59 \pm 1.58$ in Group-B. The difference between both groups was statistically significant. This is similar to the results published in literature.

Das \& Choudhury ${ }^{5}$ has reported that mean post-operative pain score in study group (open 
hemorrhoidectomy with internal sphincterotomy) was 1.60, while it was 2.32 in control group (open hemorrhoidectomy alone) with $\mathrm{p}$-value of $<0.01$. $\mathrm{He}$ concluded that internal sphincterotomy can be safely added to hemorrhoidectomy, especially for younger patients to reduce the agonizing postoperative pain and associated complications.

Another trial showed that mean post-operative pain score in control group (open hemorrhoidectomy) was $6.12 \pm 1.31$, while it was $5.32 \pm 1.25$ in the study group (open hemorrhoidectomy with lateral internal sphincterotomy) with a statistically significant $P$ value $(P=0.002) .{ }^{8}$

Galizia and his colleagues, in 2000, also concluded that addition of a lateral internal sphincterotomy to hemorrhoidectomy seems justified; it significantly improves postoperative course. ${ }^{9}$

In open hemorrhoidectomy group, 31 (24.8\%) cases had postoperative pain while in 94 (75.2\%) patients, there was no pain. In the study group, $9(7.2 \%)$ patients had postoperative pain while $116(92.8 \%)$ cases were pain-free. The difference between both groups was significant. $\quad(P=$ 0.000).

In2016, AaronMarianFernandesconductedastudy which showed that in open hemorrhoidectomy group, $>50 \%$ cases showed no or mild pain after 24 hours of surgery while in open hemorrhoidectomy plus internal sphincterotomy group, few cases showed nagging uncomfortable pain. The difference between both groups was significant with a p-value of $<0.0001 .{ }^{10}$ Another study conducted by Sumaira Otho ${ }^{11}$ reported that $100 \%$ cases of open hemorrhoidectomy plus internal sphincterotomy group had moderate to severe pain $(84.5 \%$ - moderate and $15.5 \%$ severe pain) after 24 hours of surgery. Similarly, all patients who underwent open hemorrhoidectomy alone had moderate to severe pain $(65.5 \%$ moderate and $34.4 \%$ - severe pain) after 24 hours of surgery. The difference between both groups was significant i.e. $P=0.015$. However, the pain was more severe in open hemorrhoidectomy alone group $(P<0.05)$.
Diana et $\mathrm{al}^{7}$ also concluded that internal sphincterotomy reduces significantly pain only in the first postoperative period, but not in the medium long term follow up. This is supported by the results of Kanellos ${ }^{12}$ who concluded that the addition of lateral internal sphincterotomy to open hemorrhoidectomy seems to have a positive effect on reducing postoperative pain.

\section{CONCLUSION}

Open hemorrhoidectomy with internal sphincterotomy is effective in reducing postoperative pain. It is recommended to perform open hemorrhoidectomy with internal sphincterotomy to reduce postoperative pain and discomfort in patients.

\section{Copyright $@ 31$ July, 2019.}

\section{REFERENCES}

1. Lohsiriwat V. Hemorrhoids: From basic pathophysiology to clinical management. World J Gastroenterol. 2012 May 7; 18(17):2009-17. doi: 10.3748/wjg.v18.i17.2009.

2. Li YD, Xu JH, Lin JJ, Zhu WF. Excisional hemorrhoidal surgery and its effect on anal continence. World $\mathrm{J}$ Gastroenterol. 2012 Aug 14; 18(30):4059-63.

3. Agbo SP. Surgical management of hemorrhoids. J Surg Tech Case Report. 2011; 3:68-75.

4. Song SG, Kim SH. Optimal treatment of symptomatic hemorrhoids. J Korean Soc Coloproctol. 2011 Dec; 27(6): 277-81. doi: 10.3393/jksc.2011.27.6.277.

5. Das D, Choudhury U, Lim Z. Effectiveness of internal sphincterotomy in reducing post open hemorrhoidectomy pain: A randomized comparative clinical study. Int J Collab Res Intern Med Public Health. 2013; 5(6):428-35.

6. Mukadam P, Masu S. Internal sphincterotomy as a postoperative pain relieving method in patients operated for open hemorrhoidectomy. J Res Med Den Sci. 2014; 2(1): 55-8.

7. Diana G, Guercio G, Cudia B, Ricotta C. Internal sphincterotomy reduces postoperative pain after Milligan Morgan haemorrhoidectomy. BMC Surg. 2009 Oct 24; 9:16. doi: 10.1186/1471-2482-9-16.

8. Qureshi ARZR, Azeem MA, Karim F, Dar UF, Anwar MW, Imtiaz U. Open Hemorrhoidectomy with and without Chemical Sphincterotomy: A Randomized Control Trial. PJMHS. 2015; 9(2):772-5. 
9. Galizia G, Lieto E, Imperatore V, Pelosio L, Castellano $P$. The usefulness of lateral internal sphincterotomy combined with hemorrhoidectomy in the treatment of hemorrhoids: A randomized prospective study. II Giornale di Chirurgia. 2000 Mar. 21(3):127-34.

10. Fernandes AM, Tauro LF. An evaluation of postoperative pain relief in open hemorrhoidectomy with and without lateral sphincterotomy. Saudi Surg J. 2016; 4(1):1-6.
11. Otho S, Dalwani AG, Memon KN, Shaikh NA, Sushel C, Syed BM. Haemorrhoidectomy with internal sphincterotomy: A useful method to relieve post operative pain. J Liaquat Uni Med Health Sci. 2015; 14(02):73-7.

12. Kanellos I, Zacharakis E, Christoforidis E, Angelopoulos S, Kanellos D, Pramateftakis MG, et al. Usefulness of lateral internal sphincterotomy in reducing postoperative pain after open hemorrhoidectomy. World J Surg. 2005 Apr; 29(4):464-8.

\begin{tabular}{|c|c|c|c|}
\hline \multicolumn{4}{|c|}{ AUTHORSHIP AND CONTRIBUTION DECLARATION } \\
\hline Sr. \# & Author(s) Full Name & Contribution to the paper & Author(s) Signature \\
\hline 1 & Afiya Zulfikar & $\begin{array}{l}\text { Conception of idea \& } \\
\text { manuscript writing. }\end{array}$ & \\
\hline 2 & Usman Qureshi & $\begin{array}{l}\text { Design of the article \& critical } \\
\text { analysis. }\end{array}$ & \\
\hline 3 & M. Salman Shafique & $\begin{array}{l}\text { Statistical analysis \& Editing of } \\
\text { manuscript. }\end{array}$ & salman, \\
\hline 4 & Jahangir Sarwar Khan & $\begin{array}{l}\text { Review \& Final approval of } \\
\text { manuscript. }\end{array}$ & \\
\hline
\end{tabular}

